\title{
The Politics of Qualified Moral Veganism
}

\subsection{Introduction}

Having documented that the negative GHIs associated with the consumption of animal products are wide-ranging and-in many situations-unjustified, I argued in chapter two that we should adopt qualified moral veganism. Many people, however, either willingly or unwittingly make dietary choices that are at odds with this theory. As qualified moral veganism is an ethical position, those who support it must contribute to political and legislative reforms to reduce the likelihood that people will not fulfil their duties when they make choices about what to eat.

This political project is not easy. As the policy-makers with the greatest power tend to be those who are most closely aligned with the status quo, those who seek to persuade other people of the morality of qualified moral veganism face significant resistance. Oppositions may come not only from farmers, but also from politicians, where Clements $(1995,12)$ has pointed out, in reflecting on the situation in the UK, that 'the National Farmers Union is an extremely powerful body, and it is no accident that many politicians are also farmers'. In fact, those farmers who are the most powerful are those who farm animals as funding provided by the European Union's Common Agricultural Policy has been biased towards those who own large quantities of grassland (Webster 2013, 207; European Commission 2015). Similarly, Joy $(2010,91)$ speaks of the power of agribusiness in the USA as a 'meatocracy'. This is also why investing one's hope in using the press and media to broadcast views that challenge established ways of thinking in radical ways would be naïve. In their analysis of UK national newspapers for the year 2007, M. Cole and Morgan (2011) reveal that newspapers tend to undermine veganism through ridicule, as well as through portraying vegan diets as impossible to maintain and through presenting vegans as faddists, ascetics, sentimentalists, or even hostile extremists-a general discourse that they label as 'vegaphobia'.

How to cite this book chapter:

Deckers, J 2016 Animal (De)liberation: Should the Consumption of Animal Products Be Banned? Pp. 107-129. London: Ubiquity Press. DOI: http://dx.doi.org/10.5334/ bay.d. License: CC-BY 4.0 
Those who seek to bring about radical change in relation to the consumption of animal products would therefore be advised to take heed of these challenges, to contribute to identifying them, and to try to address them, knowing that it may be very difficult to curtail the actions of those who either deliberately try to or unwittingly stifle those who espouse views that are radically different from the status quo. If the view is correct that our experiences contribute not only to the formation of our ideas, but also to the formation of our brain structures, entrenched ideas may be very difficult to challenge (Wexler 2006). Once our brain structures have developed in particular ways, it is thought that we then seek information from our environments that accords with those structures, and deny or ignore everything else. This is aptly summarised by Lakoff $(2004,73)$ : 'When the facts don't fit the frames, the frames are kept and the facts ignored' (quoted in Rees 2008).

In spite of these obstacles, this chapter considers three strategies that people with political power might adopt to promote qualified moral veganism. The first option is to educate people about the reasons underpinning qualified moral veganism in the hope that, where necessary, education will trigger behavioural change; the second is to increase the costs of animal products; and the third is to introduce a qualified ban on the consumption of animal products by turning the vegan project into a reality. After discussing these strategies' merits and demerits, I shall engage extensively with three objections that have been raised against the third strategy.

\subsection{Educating people about the reasons underpinning qualified moral veganism}

A study carried out in 2004 in the state of Victoria (South Australia), which explored, by means of a questionnaire, the attitudes of 415 people towards consuming plant-based foods, found that the strongest barriers that people invoked to the consumption of diets with low quantities of animal products was that they needed more information about such diets (Lea et al. 2006a; Lea et al. 2006b). The same study, however, found that $70 \%$ agreed with the statement that such a diet might 'prevent disease in general', but only $35 \%$ agreed with the view that it might 'help the environment' (Lea et al. 2006b, 834). Even if awareness of the environmental benefits of such diets was low, about $62 \%$ of respondents wanted to learn about such benefits. Similarly, Garnett $(2008,121)$ has made the more general claim that 'people know little about the ... implications of what they buy and eat', a claim that has also been supported by other empirical research (Joyce et al. 2008).

If many people know relatively little about the positive and negative GHIs of their dietary choices, but nevertheless show a willingness to learn more about them, the first option that policy-makers might pursue is to educate people about these GHIs in the hope that people will change their behaviour where 
required. This could be done in various ways. One way is to invest in research to expose socio-economic and psychological factors underlying food choice and to increase our knowledge about the positive and negative GHIs of animal products, particularly about the negative GHIs that have been neglected. Another is to invest in the dissemination of acquired knowledge through the press and media with the aim to stimulate people's thinking on these issues and, more generally, to promote the development of people's critical thinking skills that may help them to disentangle conflicting information and lead to changes in their values and behaviour.

There are many reasons, however, why the educational strategy is not sufficient. A first problem is that not everyone has the same educational opportunities. Consequently, educational campaigns are likely to reach some groups more than others, and, as research has found that many highly educated people may be more receptive towards considering dietary changes, highly educated people may be more likely to benefit from educational campaigns, with the result that existing health inequalities may increase (M. Kearney et al. 2000; Wardle and Steptoe 2003; Lea et al. 2006b). Even if educational opportunities could and should be equalised more, it is unlikely that individual differences in the comprehension of health information can be relegated to history. Accordingly, those people with either limited understanding or restricted opportunities to develop their understanding may be unlikely to develop modes of behaviour that accord with qualified moral veganism where they do not already embody these modes. To the extent that the problem posed by a lack of understanding cannot be overcome, some people will forgo opportunities to make positive behavioural changes. Though this does not imply that educational campaigns are wrong, it does emphasise that those who design them must be careful to avoid increasing the gaps between those who adopt relatively healthy diets and those who do not do so.

A second problem is that, even if people develop their understanding about the negative GHIs associated with problematic dietary choices, this new understanding might not be sufficient to propel them towards behavioural change. People's values may remain at odds with the values underpinning qualified moral veganism. Moreover, even if they did alter their values in ways that would support such a position, this might not necessarily result in behavioural change. The fact that 'old habits die hard', or, in other words, that there is 'behavioural lock-in', is a formidable challenge, as is well-known by those who have campaigned to protect people from the effects of passive smoking (Janson 2004). Though the dangers of passive smoking have been known for some time, many smokers who no longer expose others to the effects of second-hand smoke only changed their habits after legal changes had been made to prohibit smoking in public places (Menzies 2011). As with smoking, particular foods also fulfil social, cultural, and religious functions, and people might perceive that the meaning of these functions would be altered by dietary modifications. Research has revealed that the consumption of animal products has been particularly 
highly prized in Western culture (Twigg 1983; Fieldhouse 1986; Charles and Kerr 1988) and that it represents an important means by which men assert their dominance over women in patriarchal societies (Adams 1990). Consequently, it can be expected that many people who abide by these social conventions and hierarchies would be unwilling to give up the consumption of animal products and that many will either ignore or downplay negative GHIs-a view that has been borne out by empirical research. In the aforementioned study from Victoria, Australia, 30\% of respondents to the survey agreed with the statement 'I don't want to change my eating habit or routine', in spite of the fact that many agreed that a diet that is relatively low in animal products might be beneficial (Lea et al. 2006b, 832). Whereas a study in the European Union found that this unwillingness to change was less prominent (J. Kearney and McElhone 1999), research has also found that many consumers dissociate moral issues associated with the production of animal foods from their consumption, which explains why choices in relation to the latter are not necessarily informed by thoughts about the former (Korzen et al. 2011).

Though, in spite of these considerations, people can, and do, change habits without financial incentives (see section 3.3) or the use of legal force (see section 3.4), there is a third, more important reason why educational campaigns may not be sufficient. Many smokers might have had some desire to change for a long time, but they might have been reluctant to change their behaviour on the basis of the view that the benefits for non-smokers would be relatively small if other smokers carried on smoking in public places. A similar 'tragedy of the commons' dilemma (Hardin 1968) operates with the consumption of animal products. While those who eat more healthily may reap some health benefits associated with their dietary changes, the tragedy lies in the fact that they, as well as everyone else, would still be exposed to the wide range of negative GHIs associated with the consumption of animal products that I explored in the preceding chapters.

If people in India, for example, were to decide to adopt vegan diets, perhaps out of a concern with the processes involved with the production of ghee, they would still be exposed to many negative GHIs associated with diets that include animal products. There are many reasons why food is expensive for many people, but I argued in chapter one that an important contributing factor is the high and increasing consumption of animal products. Any Indian people who decide to adopt vegan diets would still be exposed to high food prices, and any slump in the demand for animal products in India might not result in a decrease in the production of animal products, but in producers targeting and finding other consumers who can plug the gap left by Indian vegan people. Therefore, Indian vegans might still experience the negative impacts associated with high food prices, in spite of their efforts to reduce demand. They might also not be able to benefit from eating varied vegan diets, given that world agriculture is currently focused heavily on the production of crops that can be fed to farmed animals and is controlled to a large extent by very 
powerful companies with greater interests in feeding farmed animals than in feeding people (Loughnan 2012, 228-242). They would also still be exposed to the climate change impacts that result from others consuming animal products. Some harm that they might experience may be much less obvious; for example, they might be left with food that is nutritionally inadequate when they are hospitalised (even if this possibility may be much less likely in India than in many other countries where vegetarianism is less common).

The risk of social harm, for example the psychological harm that is caused to vegans by people who introduce veganism as an interesting subject to talk about whilst consuming animal products, should not be excluded either. Vegans may also find it difficult to find work when they are invited to share meals with potential employers. They might have to 'hunt' for food for a considerable amount of time when they are eating out, interfering with any social duties that they may have. In a culture wherein veganism would be the norm, none of these issues would present themselves. In a culture that regards veganism as no more than an option that people should feel free to take or leave, those who contemplate voluntary change may refrain from doing so out of fear of social isolation. Educational campaigns must be careful to avoid contributing to this by individualising social problems and thus leaving unchallenged the socio-economic contexts wherein people live, a concern that has also been identified in relation to some campaigns to tackle obesity (Deckers 2013a).

Although some campaigns may worsen existing problems, this does not imply that there is no place for appropriate educational initiatives that aim to encourage debate on the consumption of animal products and, more specifically, on qualified moral veganism. Rather than individualising problems, such campaigns should target socio-economic contexts and, particularly, the actions of powerful actors who shape those contexts with the aim to ignore or downplay the concerns of those who are appalled by our global food system. However, it must be recognised that those who fail to minimise negative GHIs may not be persuaded to reduce their negative GHIs merely by being exposed to education. This is why investing resources merely in educational campaigns is insufficient.

\subsection{Increasing the costs of animal products}

The farmed animals' sector is currently subsidised to produce a wide range of negative GHIs. In many countries, governments privilege the farmed animals' sector over other agricultural sectors. The LEAD study, for example, claims that 'livestock lobbies have been able to exert an over-proportional influence on public policies, to protect their interests', a situation which has resulted in 'the severe under-pricing of virtually all natural processes' associated with the production of farmed animal products (Steinfeld et al. 2006, 222, 228). The European Union, for instance, provides the largest share of its subsidies to its 
farmers through its Common Agricultural Policy, which was established in 1957 with the aim to increase productivity. About 30\% of the European Union's entire budget was spent on 'farmers and market-related expenditure' in 2013, and an additional 9\% was spent on 'rural development' (European Commission 2015). These subsidies are not dispensed equally between farmers: those who produce animal products generally receive more than those who produce other foods (Lock and Pomerleau 2005; Weidema et al. 2008). The reason for this relates to the fact that payments are allocated largely in proportion to the size of farms, favouring those with access to large areas of grassland (Webster 2013, 207). A 2012 estimate claims, however, that only $6 \%$ of gross domestic product in the European Union was generated from agriculture (European Commission 2012).

Many authors have argued that in order to curtail the consumption of animal products these products should be much more expensive (Walker et al. 2005; Compassion 2007; Lloyd-Williams et al. 2008; Pelletier and Tyedmers 2010). Robert Goodland, for example, advocates the removal of subsidies from the least sustainable forms of agriculture and the introduction of a sliding-scale tax whereby the least sustainable forms of agriculture would be taxed more than the more sustainable forms (Goodland 1997). Similar proposals have been made by others (see e.g. Wirsenius et al. 2011; Nordgren 2012). This scheme could be broadened out into a negative-GHI tax-the introduction of which I proposed elsewhere (Deckers 2010) - that taxes the negative GHIs of all goods in proportion to the risks that they pose to one's holistic health.

Clearly, it is no good to tax goods highly if the tax that is levied on them only cancels out the subsidies that were provided to produce those goods in the first place. Any government initiative that aims to reduce negative GHIs through pricing mechanisms must therefore, as a first priority, ensure that products that produce large quantities of negative GHIs do not benefit from subsidies and that - where the provision of subsidies is a good idea-subsidies are provided to encourage activities that reduce negative GHIs. In this vein, the Australian Government recently introduced Australian Carbon Credit Units (ACCUs). These ACCUs provide farmers with the means to earn carbon credits, which they can earn by reducing greenhouse gas emissions or by storing carbon-for example by planting trees or by incorporating materials that contain carbon into soils-and then sell to those who wish to offset their emissions (DCCEE 2012). This system could be extended to incentivise other activities that reduce negative GHIs.

The most developed proposal along these lines is advanced by Vinnari and Tapio (2012), who argue that governments could increase the security of the supply of food, as well as of other goods, through the development of national stockpiling systems-systems that aim to secure the supply of goods at a national level to guard against natural or social threats to the acquisition of basic goods-composed of those goods that are approved of from an ethical perspective. Governments would agree to buying the cheapest ethically 
approved goods that had been produced within their country at prices exceeding those that these goods might gain on the global market, and they would then sell these to the highest bidders on the global market. In this way, producers would be provided with incentives to produce those goods that were both approved of and guaranteed to be bought by one's government at a reasonable price. National production would thus be subsidised by one's government as it would probably pay more for the selected products than the price that they might receive on the global market. The authors point out that the introduction of this system would not only lead to a reduction in the consumption of animal products, but also provide greater national food security, protect farmers more against price instabilities, and supply a wider range of foods to the global market as the compositions of national stockpiles would be likely to be more diverse (Vinnari and Tapio 2012, 52). This proposal has received little discussion in the academic literature so far, and it would be interesting to know whether this silence might be related to a perception that developing this kind of governmental intervention is unrealistic in light of our current economic situation or, perhaps, to past experiences with European policies that led to the overproduction of some goods, for example of the 'butter mountains' associated with the Common Agricultural Policy.

Some might oppose the pricing option from the conviction that the poor would be affected more negatively than the rich. As long as we live in a world where great financial disparities exist, those who are poor would be affected more than the rich by price increases in products that are associated with large negative GHIs. However, for two reasons, I do not think that this concern should undermine the value of introducing schemes that would result in products with large negative GHIs becoming more expensive. Firstly, the possibility that the poor might be affected more negatively is an argument for a redistribution of wealth, rather than an argument against pricing negative GHIs. If all the negative GHIs associated with particular products, including their effects on the poor, could be internalised in the prices that people pay, their prices would be just. Whilst this option would allow those who are richer than others the ability to consume more products with relatively large negative GHIs, the fairness of this option in relation to human poverty would depend on whether the scheme increased existing disparities. Whereas the issue of fairness is a legitimate concern if the negative GHIs on the poor are not considered adequately, it is not a necessary consequence of any such scheme. Secondly, the pricing option would lead to some products becoming more expensive, but many other products that are associated with fewer negative GHIs would actually become cheaper. They might become less expensive not only in relative, but also in absolute, terms, as we would no longer be required to spend large sums of money on remedying problems caused by the production of large quantities of goods that are associated with large quantities of negative GHIs.

It is important to recognise, however, that the health concerns posed by products with large negative GHIs may not necessarily diminish by increasing 
these products' costs. William Rees (2006b) provides the example of the Eastern Atlantic bluefin tuna (Thunnus thynnus), whose price has increased significantly but whose bodies continue to be sought in great numbers, in spite of the fact that the populations of this species, as well as those of many other fish, are in sharp decline. In fact, animal products are generally known for their low price elasticities, particularly in relatively well-off countries (D. Chen and Abler 2014). An advocate of the pricing option might try to address this problem by arguing that this does not show that the pricing option does not work, but merely that we must develop better systems to ensure that all negative GHIs are priced fairly.

Adopting the pricing option would transform our present situation, wherein the full costs of many products that result in relatively large negative GHIs are currently not reflected in their prices. However, whereas increasing the costs of animal products might reduce their consumption in capitalist societies, it addresses neither the 'tragedy of the commons' problem identified in section 3.2 that will exist unless all societies cooperate, nor the question of what ought to be done in societies that do not recognise the value of money. Finally, the question must be asked whether raising the prices of animal products is sufficient to address all our moral concerns.

\subsection{The vegan project}

It would seem odd to wish to stop paedophilia by merely making the price of having sex with children very expensive. Similarly, if animal products should not normally be consumed by human beings, it would seem to be inappropriate to put high prices on the bodies of Eastern Atlantic bluefin tuna, for example, and simply hope for the best. As we possess an animalist interest and as tuna have interests in the enjoyment of things that keep them alive, tuna should be granted rights not to be killed for food by human beings, rights which should be allowed to be violated only in exceptional circumstances, for example when a human being is left at sea with nothing else to eat. As we create laws to counter the actions of paedophiles and many other actions that harm the fundamental interests of human beings, we should also create laws to protect Eastern Atlantic bluefin tuna and-more generally-to prohibit activities that fail to minimise negative GHIs.

When we consider the farmed animal industry, the argument has been made that the negative GHIs associated with the large-scale use of antibiotics in the production of particular farmed animal products are so significant that they justify a ban on the use of prophylactic antibiotics (Anomaly 2010). However, as other aspects of the animal industry do not fare much better as far as their negative GHIs are concerned, it would seem to be appropriate to ban the consumption of animal products for all human beings who would fail to minimise negative GHIs by consuming such products. In earlier work, I referred to the 
ambition to create international and national laws to introduce such a qualified ban as 'the vegan project' (Deckers 2013b). Though it may be-in Caney (2008, 539)'s words-'unreasonably demanding' for human beings to avoid consuming animal products in some situations, in many situations it is not. To the contrary, in many situations it is entirely unreasonable to allow human beings to continue eating animal products. As I have sketched in the preceding chapters, many people who consume animal products fail to minimise negative GHIs through their dietary choices. I have shown that this is so for a number of reasons, including: that they may be more likely to get ill-as will be documented more fully in the appendix-and thus to require treatments that may be funded partly by others; that they are more likely to make other people ill; that their diets require more land and cause more land degradation; that their diets use more water and contribute more to water pollution; that their diets use more fossil fuels and contribute more to climate change and other atmospheric concerns; that they impose more pain, suffering, and death on animals in many situations; and that they cause psychological harm to others who lament the fact that they conceive of the bodies of animals as things that can be routinely eaten.

It is, of course, quite possible that some people will not class the same sorts of things as those that I have mentioned here as negative GHIs or that they will give far less moral significance to some of the negative GHIs that I mentioned. If the fact that hardly anyone adopts vegan diets can be taken to suggest that people do not attach great moral significance to the concerns that I have expressed in chapter two, many policy-makers might consider a qualified ban to be a step too far from a political perspective. This, however, is misguided, as the question whether we ought to adopt a qualified ban does not depend on the concerns I have outlined in that chapter. Such a ban could also be justified merely on the basis of the narrower negative GHIs associated with zoonoses and with the human use of the environment that I described in chapter one. Those animal products that are associated with those negative GHIs that are widely agreed to exist could, accordingly, be singled out for a ban. For example, many people may agree that climate change is associated with very significant negative GHIs and that drastic action is required to avert dangerous climate change. Accordingly, the policy-makers of nations that fail to minimise negative GHIs in this domain might decide to curtail the consumption of animal products.

Some people who live within those nations, however, may object to a qualified ban on the basis of the view that such a ban would be an unjustifiable infringement on their personal liberty. My response to this is that such infringements are justifiable provided that those who have legitimate political power justify the infringement on personal liberty as necessary to safeguard holistic health. It might be objected that people could do all sorts of things to limit their negative GHIs, and that focusing on the consumption of animal products would be unfair on those who would much rather curtail 
their negative GHIs in other domains instead. This objection, however, is not compelling. As long as people's interests in holistic health are still being jeopardised, there is a compelling justification to limit negative GHIs. It might still be appropriate to ban the consumption of animal products even in situations where the consumption of animal products does not produce more negative GHIs than the consumption of other products that could be eaten to obtain a similar quantity of health benefits. By analogy, a government that decided to ban car travel inside city centres might not necessarily wrong those who avoided exceeding their fair share of emissions and who contributed little to inner city pollution through the use of their car before the introduction of such a ban. I accept the view that democratic governments should have the authority to make decisions that may curtail the individual liberty of some people to spare others from significant harm, even if the people in question did not cause any of the harm that ought to have been avoided before the introduction of the restriction.

Similarly, it could be argued that adopting a qualified ban on the consumption of animal products would not necessarily restrict the liberty of those who abide by the duty to minimise negative GHIs. Governments might simply adopt the view that the easiest way to tackle irresponsible consumption that harms others is by eliminating those things that we could do without. Since many people fail to minimise negative GHIs, the question whether the consumption of animal products is a domain that justifies such an approach must be debated with extreme urgency. If I were a dictator, I would introduce a qualified ban with immediate effect, provided that I did not think that doing so would increase negative GHIs, for example if there was a good chance that it would trigger a significant amount of violent resistance. As I am not a dictator, and since I do not aspire to become one, it is my aim to contribute to democratic processes that would introduce qualified bans on the consumption of animal products. Even if some people might oppose such a scheme, this does not imply that it would be wrong to implement it. However, great care must be taken to avoid that any well-intended legal changes trigger undesirable negative GHIs, for example through the possibility that some people who oppose such a scheme might resort to violent resistance.

Whereas I shall not elaborate on the sorts of democratic processes that should be adopted to move us in the direction of realising the vegan project, it is nevertheless clear that it is paramount that our increasingly urbanised population be well-informed about the methods that others use to produce their food. Where information that is crucial to make informed decisions is actively hidden, for example by those producers who try to hide how food is produced from the eyes of the public, it has been argued that some legal infringements, for example trespass onto private property, may be required (McCausland et al. 2013). I believe that this is right, and that we should generally prefer non-violent methods to reach our goal. 
Some might claim that violent means should also be embraced. They might argue that some human beings are violent towards other animals and that violent actions against these human beings ought to be justifiable where there is a good chance that they might reduce the sum total of violence. I am not persuaded by this line of reasoning as most violent actions against those who are perceived to mistreat animals may alienate those who mistreat them as well as others who are not able to see that this treatment of other animals is as problematic as it is claimed to be by opponents of this treatment. Whilst there may be a place for violence in some situations, for example to block someone who is about to vent their frustration on an animal by hitting the animal, those who support the vegan project must, in order to realise their ambition, be mindful of the fact that public support is unlikely to grow with the use of strategies that may strike large numbers of people as deeply unacceptable.

Meanwhile, supporters of the vegan project would also do well to show their limited support for the most benign ways in which animal foods could be provided for human consumption as long as their ambition has not been realised. In this light, they should, for example, show their support for the consumption of animals who die naturally, or of those who are killed justifiably. They should also support the production and the consumption, by others, of lab-grown flesh if doing so minimises negative GHIs in a particular situation where it is reasonable to believe that it would not jeopardise the ambition to minimise negative GHIs in the long-term. In this respect, it is worth noting that the production of lab-grown flesh has been associated not only with a reduction in concerns related to the human treatment of other animals, but also with a decrease in environmental issues relative to conventional production methods used in the farmed animals' sector (Tuomisto and de Mattos 2011). Even if there is much uncertainty regarding the latter due to the limited technological progress that has been made so far, Tuomisto and de Mattos (2011) expect that the development of lab-grown flesh may be associated with significant decreases in energy use, greenhouse gas emissions, land use, and water use.

In spite of my contention that the consumption of animal products generates many negative GHIs, a total ban on the consumption of animal products cannot be justified. All human beings should be granted a right to health care, which includes a right to food (UN CESCR 1999). For some, this right would be jeopardised unjustifiably by a complete ban. Some people, for example, may have specific physiological demands that may not be able to be satisfied without the consumption of animal products. The high nutrient-density of many animal products, for example, might be critically important for some people who suffer from AIDS and who do not have sufficient access to adequate plant foods (Randolph et al. 2007; Roubenoff 2000). Some people may live in areas where the consumption of alternatives to animal products would produce a larger quantity of negative GHIs - for example those people with limited resources who live at high latitudes where diets that rely solely on plant foods do not 
provide adequate nutrition or the same amount of food security that is provided by a more varied diet.

\subsection{Three objections to the vegan project, and their refutations}

In the remainder of this chapter I shall consider three objections that have been raised against the vegan project. The first is that it is pointless to focus on a qualified ban, simply because the vast majority of people are not ready for it. The second is that the vegan project is unacceptable as it would undermine human food security. The third contends that the vegan project alienates human beings from nature.

\subsubsection{First objection: People are not ready to adopt a qualified ban, so it is pointless to pursue such a ban}

A first objection to my proposal comes from those who think that introducing a qualified ban simply will not work because it does not have enough public support. On this basis, many argue that it would make more sense to focus on small objectives that might gain support, rather than risk putting people off by focusing on objectives that many people will oppose vehemently. Thus, Fetissenko $(2011,150,155)$ has argued that arguments that do not focus on narrow personal health and environmental effects associated with the consumption of animal products have 'limited persuasive appeal', and that those people who wish to persuade people to adopt vegan diets might have more success if they focused on those effects and on 'advocating for (slightly) better conditions in which "farm animals" live and die'.

As I write these lines, I am reminded of my visit to Australia in October 2012. At this time, a lot of media attention was given to the fact that many animals were transported over vast distances to the Middle-East and to Malaysia, where they were treated and slaughtered in many ways that Australians did not find acceptable. Apart from this, the only animal issue that gained significant attention was the fact that many Australians still buy eggs from caged, rather than from free-range, hens. If the media's role is merely one of reporting what is going on, it may not be right to blame the media for focusing on these two issues, and to ignore all else. There is no doubt that the reason why the media was highlighting these issues relates to the fact that many organisations that speak up for animals hope to bring about change by means of small, incremental steps. I am not opposed to small changes for the better, but I do believe that there are good reasons to think that many people are actually capable of taking a giant leap forward, at least if they are prepared to be consistent. The reason why I believe this to be the case is that some nations already have some laws in place that, if they were extended consistently from one domain (the use of 
animals for research) to another (the use of animals for food), would point in the direction of qualified moral veganism.

In this regard, Council Directive 2010/63/EU on the protection of animals used for scientific purposes provides a good example. With this directive, which member states of the European Union were expected to have fully implemented in 2013, the European Union tried to improve the conditions of the use of nonhuman animals in research. In most European Union law, the articles that form the core of the legal text are preceded by a number of recitals that provide reasons underpinning the law. It is important to recognise that these recitals are not considered to have independent legal value', but that they 'can expand an ambiguous provision's scope' and cannot 'restrict an unambiguous provision's scope' (Klimas and Vaiciukaite 2008,3). Directive 2010/63/EU is a fascinating text, particularly because of recitals 10 and 12 . Recital 10 posits that the 'Directive represents an important step towards achieving the final goal of full replacement of procedures on live animals' (Council Directive 2010/63/EU). Recital 12 states that 'the use of animals for scientific or educational purposes should ... only be considered where a non-animal alternative is unavailable' (Council Directive $2010 / 63 / \mathrm{EU}$ ). The reason why these recitals are so interesting is that they would have radical implications for the use of animals for food if people were prepared to be consistent. This is clear if we replace a few key words in recital 12: 'the use of animals for' food 'should ... only be considered where a non-animal alternative is unavailable.' Indeed, the 'final goal of full replacement' that recital 10 talks about seems to be within the reach of most people who live in the European Union today: most people there have sufficient non-animal alternatives available to feed themselves. If people were consistent, most people who live in the European Union, as well as many who live in other places, would obtain adequate nutrition to maintain good health without the need to consume animal products.

In the core of the legal text, paragraph $\mathrm{d}$ of article 38 stipulates that all project evaluations must satisfy 'a harm-benefit analysis ... to assess whether the harm to the animals in terms of suffering, pain and distress is justified by the expected outcome' (Council Directive 2010/63/EU, art. 38, par. d). Though the law does not provide clear guidance on when the harm might outweigh the benefits, it is likely that any research proposal that aims to perform an experiment involving the killing of animals to find out whether people might obtain extra enjoyment (and, if so, how much) from eating animal products compared to eating plant foods would fail any plausible 'harm-benefit analysis' that is in line with the spirit of this law. In situations where other foods could be consumed without increasing negative GHIs, it is hard to think what arguments, other than such an 'extra enjoyment' argument, those who support the consumption of animal products could bring to the table to argue their case. Other goals that could be invoked in the context of research on animals, such as the desire to keep people in their jobs or to provide enjoyment to those who like to experiment on animals, would similarly be unlikely to tip the balance in favour of the benefits for any research ethics committee engaged with such 'a harm-benefit analysis'. 
Whereas the critic might object that the law may only be interested in the avoidance of unnecessary harm upon living animals, rather than in the use of animals as such, it must be pointed out that recital 12 does not actually specify whether the restriction would apply to animals who were dead already. However, even if we grant that the law may not intend to curtail the use of animals who have died naturally or who have been killed accidentally, a plausible reading of the reasoning underlying this law supports one of the central objectives of the vegan project: to eliminate the killing of animals where this is motivated by the desire to consume their bodies in situations where human beings are able to enjoy adequate alternatives that produce fewer negative GHIs. It is not consistent to demand that animals should only be used for scientific purposes 'where a non-animal alternative is unavailable', but to allow the use of animals for food merely to satisfy the trivial human interest in eating animal products where better alternatives are available.

Andrew Knight $(2011,16)$ estimates that at least 126.9 million vertebrates were used in experiments in 2005. This is a small fraction of the number of animals who are killed to provide human food. According to a very conservative estimate by the organisation Animals Deserve Absolute Protection Today and Tomorrow, based on data collected in 2003, more than 150 billion animals are killed for human food every year (ADAPTT 2012). Therefore, more than 1,200 animals are killed to provide food for every animal who is killed for research. Consistency demands that further legal reform be introduced to harmonise our law on the use of animals for research with the vast numbers of animals that human beings use for food, which-as I have documented in the preceding chapters-imposes great harm not only upon nonhuman, but also upon human, animals.

The moral inconsistency that underlies our laws must also be resolved to increase the chance that the harm-benefit analysis that Directive 2010/63/ EU talks about be carried out with sincerity. It is highly likely that the lives of animals used in research will continue to be regarded as cheap unless people embrace the vegan project. When many people continue to consume animal products, even where adequate alternatives that minimise negative GHIs are available, researchers who have been trained in the art of justifying their research in terms of need are unlikely to face significant opposition when they argue for the necessity to carry out particular research projects. In this light, it should not come as a surprise that a significant number of those involved in the research industry resist the use of alternatives, are careless in their study designs, and are reluctant to engage in serious study of previous work, resulting in needless duplication (A. Knight 2011, 98).

Though the articles of Directive 2010/63/EU focus mainly on moral concerns with the infliction of pain and suffering, its recitals question the use and the killing of animals for unnecessary research. Moral consistency demands that further European Union legal reform be introduced to prevent billions of animals from being killed completely unnecessarily. Other jurisdictions 
that agree that animals should not be used for unnecessary research ought to bring about similar reform. An additional moral concern underlying the vegan project-the taboo on using animals who have died naturally, accidentally, or painlessly - may not be supported by the recitals of Directive 2010/63/EU, but a culture that develops strong reservations about killing animals in order to consume them might also be expected to develop strong reservations about consuming animals at all. If the reason why many vegans would not wish to eat animals can be understood not merely in light of a concern with the imposition of pain, suffering, and death upon animals-a necessary aspect of most diets that humans adopt-but also in light of a concern with using animals for food at all, it would be appropriate for adequate legal reform to target the consumption of animal products as such.

Whereas the European Union has not moved into the direction of the vegan project, perhaps partly because of this legal inconsistency, a 2014 legal change in the Indian city of Palitana-a city of around 65,000 people in the state of Gujarat-does appear to be largely in line with what the vegan project seeks to accomplish. To my knowledge, Palitana is the world's first city where the slaughter of animals as well as the sale of flesh and eggs has been banned by local law, effective from 14 August 2014 (Niazi 2014; van Popering 2015). The basis for the ban stems from the ethics of Jainism, particularly from its central focus on its interpretation of the principle of ahimsa (non-violence), which has been understood to demand vegetarianism by many, including the circa 200 monks who went on hunger strike to push for this legal change. Whereas the content of people's diets in Palitana may therefore be similar to the content of the diets of those who are moved to qualified moral veganism through considering the arguments developed in this book, the underlying ideology is bound to be markedly different.

In spite of this difference, we should not conclude too quickly that there is no overlap between these ideologies, as the principle that we should try to avoid inflicting pain, suffering, and death upon animals appears to be closely related, even if I know relatively little of Jain ideology, to the principle of ahimsa. Indeed, van Popering (2015) has noted that Jains may even relate positively towards adopting a more general taboo on the consumption of the flesh from animals.

Therefore, I believe that it is justifiable to conclude that there is some evidence to suggest that a growing number of people are ready to take a giant leap forward, a trend that has also been observed in some other countries, for example in the USA and in Australia (Pendergrast 2016). Apart from these signs that the times are changing, there is at least one further reason why it may not be appropriate to focus merely on small, incremental steps. The idea that people should be allowed to use animals for food in situations where doing so cannot be justified might be strengthened by campaigns that merely tinker around the edges. Those who focus their attention on the pushing of deckchairs may lose sight of the possibility that the boat might be sinking. Those who believe that the ship is sinking will hardly be satisfied with an approach centred on the 
pushing of deckchairs. Accordingly, it is by no means pointless to focus on the adoption of a qualified ban.

\subsubsection{Second objection: The vegan project undermines human food security}

The second objection is that realising the vegan project would result in a predominantly vegan global agricultural system, and that such a system would compromise the nutritional adequacy of human diets unjustifiably, either by not providing sufficient food for all people who need to consume animal products in order to be healthy now or by jeopardising long-term food security.

In reply to the first concern, it can be noted that many people are likely to fail to minimise negative GHIs by consuming animal products; however, to the extent that they do not do so-say, if they needed to consume animal products because of dire health needs - it could be argued that the farming of animals should still be allowed to cater for their needs. Indeed, I must emphasise that I do not wish to contribute to legal reform that might jeopardise any human being's right to adequate food. However, when it comes to thinking about how this right might be satisfied, it must be pointed out that the demise of the farmed animals' sector may not necessarily be a problem. The consumption of products derived from most farmed animals differs from the consumption of wild or feral animals in a number of morally significant respects: the lives of the latter tend to be controlled to a much lesser extent by human beings; no arable crops must be grown deliberately to feed them; they present no manure management problems; no or fewer drugs are required to treat them; and they pose fewer direct human disease threats as populations tend to be more spread out and further removed from human beings. In light of the concerns I expressed in the previous chapters about the human control of animals and the health issues associated with farming animals, the consumption of products derived from wild and feral animals must be preferred to the consumption of farmed animal products.

Hunting advocates might now warm towards my project, but they might be getting hot too quickly. I am not arguing for an increase in hunting per se; rather, I suspect that the numbers of wild and feral animals-who would be able to roam freely to some extent-would increase as the farmed animals' sector contracts, and I would support the killing of these animals for food only to the extent that doing so would be required to ensure that all human beings can be provided with adequate nutrition in situations where this aim cannot be achieved by other means without increasing negative GHIs. I hypothesise that sufficient quantities of animal products would still be available to feed those human beings who must consume animal products out of dire health needs if many relatively affluent countries in temperate climates prohibited the farming of animals. Should the quantity of flesh provided by wild and feral animals not be sufficient, it may then be necessary to allow the farming of some animals for 
food: the vegan project does not turn its back on those who would compromise their health by avoiding the consumption of animal products.

Whereas it may not intend to ignore some people's nutritional needs, the vegan project has nevertheless been criticised for its failure to buffer human beings sufficiently against the constant threat of food scarcity. Fairlie (2010) devotes several pages of his book Meat: A Benign Extravagance to this claim, arguing that a predominantly vegan system would lack the benefits that are brought about, within a mixed system, by the existence of a greater number of a range of farmed animals and of the greater number of the arable crops that are fed to them. These would act as a 'buffer', protecting human beings from food shortages caused by a rising human population, by crop failures, or by the combination of these two factors (Fairlie 2010, 114-118). If this claim is valid, vegan societies might also be free-riding on a general duty to take appropriate measures to secure food for all human beings.

With regard to the population issue, Fairlie $(2010,109-113)$ points out that a predominantly vegan global society might grow larger than a population that adopted a mixed system. The problem with this is that, unlike societies that slaughter a proportion of their domesticated animals once they reach carrying capacity (as what the Maring of New Guinea do with their pigs) and before the animals start intruding on land occupied by neighbouring societies, such a vegan society would lack the option of slaughtering a significant number of animals to free up space to grow crops to feed the human population more efficiently once it reached global carrying capacity. Though this possibility must be taken seriously, especially since the global human population is already at an all-time high, I do not think that a predominantly vegan global society would necessarily carry on increasing its population until it reached a situation where it would teeter on the brink of exceeding its carrying capacity. Rather, I believe that, in light of my general concern with how human beings control and dominate the lives of others, those who advocate for the creation of such a vegan society must also take and support measures to control the human population so that not only future generations of human beings, but also many other organisms whom we share this planet with, are allowed to thrive.

Even if we accept that a largely vegan population adopting a predominantly vegan agricultural system may not possess the tendency to become any larger than a population dependent on a mixed agricultural system, Fairlie maintains that the former population would still be buffered from food scarcity to a lesser degree by being more vulnerable to crop failures, as the existence of a sizeable number of a range of particular farmed animals protecting humans from the negative impacts of such failures would be lacking. Though in a mixed system some arable crops are grown to feed farmed animals, Fairlie rightly points out that, in times of crop failures, human populations could resort not only to eating the farmed animals, but also to eating the crops that had been destined to feed those animals. In a predominantly vegan system, this option would be almost absent, so that the risk of human starvation through crop failure would be much 
greater. I share Fairlie's concern with food security, and therefore I would not be willing to advocate the vegan project if it increased our vulnerability to hunger resulting from crop failures. The challenge that remains is to argue that it is possible to establish both global and local vegan projects that do not increase human vulnerability to crop failures compared to mixed systems. I would like to address this challenge by pointing out that there are a number of reasons to believe that, in many locations, the adoption of a predominantly vegan system may be able to provide as much human food security as a mixed system.

Firstly, as mentioned before, it is highly likely that the completion of the vegan project would be accompanied by a significant rise in feral and wild populations of animals. Whereas it may be more difficult to catch, kill, and butcher these animals and to provide the products derived from them to those who need them, their nutritional quality may be better than that of the products derived from farmed animals (Crawford et al. 2010; Hoffman and Wiklund 2006).

Secondly, though the vegan project seeks to limit the number of mixed systems, it does not wish to eliminate them where doing so would increase negative GHIs. Some people in India, for example, lack access to private land where they could grow crops. For them, owning a cow who can graze on public land may mean the difference between life and death (Devendra 2007). It would seem to be highly unethical to deny them the option to use a cow if the socio-political factors that contribute to these people's precarious situations cannot be ameliorated.

Thirdly, even a vegan agricultural system might justifiably use animals in situations where not doing so would increase negative GHIs. In some situations, animals could be kept for traction or transportation, for example. Whilst vegan agricultural systems would not keep animals in order to kill them to provide human food, in times of great need with morally more problematic alternatives, some of these animals' body parts could be eaten after they had died accidentally or naturally or after they had been killed justifiably, for example on compassionate grounds.

Fourthly, some edible arable crops that are grown are not used for food, but for other purposes, for example to produce alcohol. As recognised by Fairlie (2010, 116-117), these crops could be used for food in times of scarcity. In addition, a growing amount of arable land is used to produce alternatives to fossil fuels. Whereas it would be prudent to grow energy crops that could, when necessary, be used for food purposes as well, the GHIs of any proposals to grow and use potential food crops for biofuels must be very carefully considered. As Fairlie $(2010,117)$ recognises rightly, two major concerns in relation to this are that the energy that is provided by many crops that are currently used for biofuels is rather small and that the distillation processes involved rely frequently on large central facilities. Therefore, a challenge that must be addressed is whether any (parts of) crops that either are already or could be grown for other purposes could be used for food in times of scarcity without increasing negative 
GHIs compared to those that would be produced if the land on which they were grown had been used to feed farmed animals. In spite of this concern, I do not think that a predominantly vegan society would necessarily rely more on the production of inefficient biofuels than an alternative society would to maintain the same level of food security. Other strategies could be pursued. Fairlie (2010, 117) mentions the option of 'banking food in state controlled granaries which maintain sufficient surpluses'. More generally, as a result of past technological advances, our abilities to store crops for a long time and to transport them to those who need them have grown considerably. Advocates of the global vegan project should make sure that further research is carried out in these domains and that all available technologies are used in the interests of maintaining or promoting human food security without increasing negative GHIs.

Finally, it is highly likely that the wider adoption of vegan diets would stimulate interest in growing a wider range of vegetables and fruits. This might make the food system more resilient, thus reducing the risks posed by crop failures and by any increases in malnutrition and starvation that might result from these crop failures.

I conclude that the completion of the vegan project would not compromise the needs of those who need animal products out of dire necessity and that it would not jeopardise long-term human food security either.

\subsubsection{Third objection: The vegan project alienates human beings from nature}

Fairlie $(2010,217)$ also contends that those who advocate for the vegan project are, allegedly like Singer, 'blissfully ignorant about the perils of growing vegetables. Fairlie (2010, 219-220)'s claim could be labelled the 'fence' argument as he argues that a vegan agricultural system would require the building of very substantial fences resembling 'the fence around Glastonbury festival'-a large popular music festival held annually in England-to keep out pests. This argument relates to the likelihood that, with the demise of domesticated animals, the number of feral and wild animals would increase, resulting in a greater need to keep them away from the arable crops that are grown for human consumption. Fairlie $(2010,220)$ contends that 'the fence represents a logical conclusion of the vegan project [and] the most graphic symbol of the rift between humanity and nature.' Thus, the completion of the vegan project would also result in 'millions of people living on the wild side of the fence' losing their livelihoods (Fairlie 2010, 225). Fairlie's 'fence' argument addresses a number of concerns that should be explored. Nevertheless, I think the argument is not without its problems.

The fence that Fairlie dreads would be erected should the vegan project be successful is already there. Domesticated animals must also be fenced in to avoid their encroachment upon arable crops. Admittedly, fences would need to be more robust to withstand the-arguably-greater abilities of wild and 
feral animals to transcend boundaries, and we would need to have more of them to be able to cope with burgeoning numbers of such animals in a world wherein more space would be occupied by land that was managed to a lesser extent by humans. Fairlie conjures up the image of a relatively small number of large fences surrounding huge nature reserves, as suggested by his use of the phrase 'the fence' in the singular. In reality, it is likely that the system envisaged by the vegan project would consist of a large patchwork of fences erected both within wildlife areas that are relatively free from human activity and outside those areas.

Whereas the ways in which the land would be carved up in a predominantly vegan system might therefore not be as dissimilar from the present situation as he portrays, Fairlie nevertheless asks profound questions about the place that human beings should occupy within the natural world. In Fairlie's opinion, the fences that would be required to support the vegan project would alienate us from the natural world. However, it must be asked whether it is the vegan project or the agricultural project that marks our separation from nature. In fact, our separation may pre-date the time when our species made the transition to a farming way of life. Before the advent of agriculture, hunter-gatherer societies already separated themselves from nature by building shelters. When man ('Adam') and woman ('Eve') were banished from the garden of Eden-as narrated in the Book of Genesis-humans took up agriculture and started building fences to separate themselves further from the rest of nature, or from what is frequently referred to simply as 'nature' or 'the natural world'. Regardless of one's view about the attraction of the garden of Eden-which was not much of a 'garden' anyway-a return to the land of Eden is, at least in the short term, not desirable in light of the size of the expanding human population, at least if we adopt the view that all human beings have a right to adequate nutrition. In other words, it is not desirable for all human beings to become hunter-gatherers again as the collapse of agriculture would-at least in the short term-result in an inability to feed all human beings.

The question remains, however, whether the vegan project alienates us further from nature. Fairlie is not the only one who has made such a claim: a similar one has been made by Pollan (2006, 321-322), who asserts that 'the writings of the animal philosophers' display 'an abiding discomfort not just with our animality, but with the animals' animality, too', and that '[animal philosophers] would like nothing better than to airlift us out from nature's "intrinsic evil" - and ... take the animals with us. Pollan wrote this comment in the context of a discussion of predation, where his basic argument boils down to this: as some animals predate on other animals, so should we. Similarly, as some of our domesticated animals are predators, we should not deny them the flesh of other animals. The problem with both of these claims is that the conclusions do not follow from their premises. In spite of this, Pollan does raise a fair point that may apply to those philosophers who may call, together with Nussbaum $(2004,317,315)$, for 'the gradual formation of an interdependent 
world in which all species will enjoy cooperative and mutually supportive relations with one another' or 'for the gradual supplanting of the natural by the just', and who would, accordingly, use the fact that 'animals will die anyway in nature' as an argument to justify their being killed by people, where this 'might well be preferable to allowing the animal to be torn to bits in the wild or starved through overpopulation'. Yet, ironically, Pollan $(2006,321)$ also takes issue with the rawness of amoral nature, as he uses it as an argument for domestication on the same page as his plea for a greater recognition of what nature really is.

Though Pollan $(2006,326)$ rightly asks vegans to recognise that 'killing animals is probably unavoidable no matter what we choose to eat' and Fairlie $(2010,225)$ rightly questions the attitudes of those vegans who know very little about what is involved in the production of their food (epitomised perhaps by those who belong to what he calls 'soybean civilisation'), the vegan project might actually connect humans more with 'nature' by a renewed emphasis on growing fruits and vegetables and by questioning the fact that humans have alienated other animals from 'nature'. No participation in 'Pork Camp'-a 'DIY-slaughter' meeting that occurred twice in Germany in 2011-or in Dennis Buchmann's 'Meine kleine Farm' - where consumers can vote on which pig will be slaughtered next and can afterwards buy products made from the pigs-is required to reconnect with nature (Gutjahr 2013). Simplistic proposals to reconnect with nature through embracing new celebrations of carnivory ignore the fact that the farmed animals' sector has taken a great deal of control away from the animals who have been domesticated and who are alienated from the natural environments wherein their wild ancestors used to live. Some domesticated animals would not even be able to live anymore without human assistance. Stark examples are breeds of animals, for example domesticated turkeys and the Belgian Blue breed of cows and bulls, who have largely lost the ability to reproduce without human intervention.

Fairlie is right to suggest that a predominantly vegan agricultural system would not be able to avoid controlling the lives of animals, whose movements must be controlled to protect arable crops. However, the difference between a mixed and a predominantly vegan agricultural system is that in the former system humans set out to control the lives of farmed animals by planning when the latter come into existence, where and how they spend their lives, and when they are killed, whereas in the latter most animals would be either wild or feral and their lives would not be controlled by human beings unless they presented a serious threat to significant human interests, for example when controlling them would be required to protect arable crops. Most animals would be allowed to roam freely unless they presented such a serious threat to important human interests, in which case a predominantly vegan system would have to use measures to control their movements. Whilst this could be done by fencing them out in many situations, in some situations it may be necessary to kill some animals, for example when pigeons pose a significant threat to arable crops and cannot be deterred. In many situations, I believe that-in accordance with the 
principle of safeguarding nature's integrity - it is better to fence out wild and feral animals than to fence in domesticated animals.

An interesting question remains whether it would also be acceptable to kill wild and feral animals merely on welfare grounds. On this issue, Webster (2013, $46,197)$ speaks of 'well-meaning but catastrophic attempts in Europe to manage wildlife reserves with grazing animals that are not harvested for food, because it would not be "natural", but left to die of starvation in a devastated habitat', providing the example of the rewilding project in the Oostvaardersplassen in the Netherlands. To the extent that human beings were responsible for eliminating predators, they would seem to be accountable for the agonising deaths that some animals may suffer as a result of this lack of predators (as some animals may die more slowly than in an environment where they are exposed to predators), which I believe is an argument for killing animals who might be thus affected. However, I am cautious here as we must not fool ourselves into believing that a death caused by a large predator such as a wolf is necessarily better than a death caused by a small predator such as a micro-organism.

Fairlie $(2010,225)$ envisages that the completion of the vegan project would present someone living in an area that had been designated to become a new wildlife area with the stark choice of 'becoming a tourist guide or vegan gamekeeper' or of migrating to a place where they could become an arable farmer. However, these need not be the only options if relatively wild areas could be created and used for a wider range of other human purposes that would be compatible with nonhuman animals living there. Whereas Fairlie is correct in stating that more land would be set aside for nonhuman animals to roam freely within a predominantly vegan system, a large amount of the land that would be freed up by the demise of domesticated animals could still be managed for human purposes, for example to produce energy alternatives to fossil fuels. In this way, the fact that employment within the farmed animals' sector would diminish could be accompanied by the creation of new labour opportunities. To give some examples, a larger number of people would be involved with the erection of fences and with work in forestry management, and a number of plants that grow either with little or without cultivation and that may be relatively unattractive to or not be used by other animals could be harvested for medicinal or nutritional purposes.

To put it in a nutshell: in spite of the fact that Fairlie is right that more efforts would be required to protect arable land from wild and feral animals, I am not convinced that the completion of the vegan project would alienate human beings further from nature.

\subsection{Conclusion}

I identified three strategies that governments could adopt to curtail the negative GHIs associated with the consumption of animal products. There is no 
doubt that greater investment in research and education is required, but there are several problems associated with the ambition to try to bring about dietary change merely through educational campaigns. The first problem that I described is that not everyone has the same educational opportunities, so that well-intended but poorly targeted campaigns may increase any existing health inequalities between those who have particular educational opportunities and those who do not. Though good campaigns could try to decrease this gap, many people with limited understanding of how their food choices affect the health of others are likely to persist in their usual habits. The second problem is that people's values may be so different from those that underlie qualified moral veganism that they would simply refrain from taking personal steps to reduce their negative GHIs or that they may refrain from doing so even if they have similar values. A final problem that I highlighted is that people who commit to qualified moral veganism in a culture wherein this dietary position is not enforced would still be exposed to avoidable negative GHIs, which is why few may adopt such a position in the first place.

The second strategy that could be pursued, to change the financial systems that allocate taxes and to provide subsidies in order to discourage the production of goods that produce unacceptable negative GHIs, may be more likely to result in compliance than the first option because of the significant role that many people attribute to the value of money in capitalist societies. However, international cooperation would be required and it would still not work in societies that do not recognise the value of money. A further problem with this option is that some moral theories, for example the duty-based theory adopted here, do not accept the view that everything should be exchangeable for money. In some situations, it is our duty not to consume animal products, and it is not appropriate to consider that this duty might be dissolved in exchange for money. This is why I defended the third strategy, a qualified ban on the consumption of animal products. Though the vegan project would be justified if my moral theory is accepted, I argued that even if governments were to adopt the view that we have no duties towards other animals, a qualified ban could still be justified merely on the basis of our duties to give some recognition to the human right to health care, as giving full recognition to this right would in fact require that attention is also given to our duties to other animals as good human health cannot be achieved without this inclusion.

I considered three objections against the vegan project, arguing that it is not pointless to focus on a qualified ban, that the ban need not necessarily undermine human food security, and that it does not alienate us from nature. In my response to the first objection I highlighted that there is some evidence that many people are ready to embrace the vegan project provided that they are willing to be consistent, a theme that will be explored further in my next chapter. 